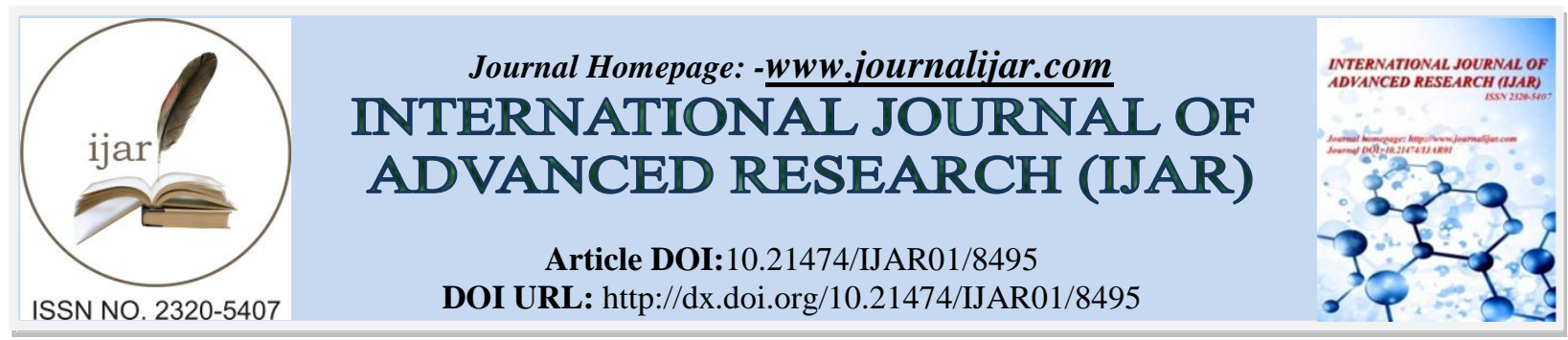

RESEARCH ARTICLE

\title{
COMPARATIVE STUDY OF ACCURACY OF BIOMETRIC FORMULAS OBTAINED BY APPLANATION A-SCAN BIOMETRY.
}

V a n p kumari oruganti ${ }^{1}$, k. Venkateswarlu ${ }^{1}$, kaavyahanuraj kolalapudi ${ }^{1}$ and p.shyam sundar ${ }^{2}$.

1. Junior Resident, Ophthalmology, Andhra Medical College, Visakhapatnam.

2. Assistant professor, Ophthalmology, Andhra Medical College, Visakhapatnam.

\section{Manuscript Info}

Manuscript History

Received: 04 December 2018

Final Accepted: 06 January 2019

Published: February 2019

\section{Abstract}

Aim of the study: To evaluate and compare the accuracy of different intra ocular lens (IOL) power calculation formulas for predicting post operative refraction in eyes of different axial lengths using applanation A scan biometry

Methods: In prospective study, conducted in GREH, Visakhapatnam with 50 eyes.Axial lengths were calculated by applanation A-scan biometry. All eyes were divided into three groups according to AL: short $(<22.0 \mathrm{~mm})$, average $(22.0-25.0 \mathrm{~mm})$, and long $(>25.0 \mathrm{~mm})$ eyes. IOL power calculation was done using the five Formulas SRKII, SRK/T, HOLLADAY 1, HOFFERQ, and BINKHORST 2. All patients were subjected to SICS with PCIOL implantation under local anaesthetia.The implanted power of IOL was based on SRK II formula. Final refraction was measured 6 weeks postoperatively.Post-operative spherical equivalent (SE) was calculated and compared with predicted refractive error using each biometric formula.

Results: All formulas had a significantly lower MAE in comparison with BINKHORST II formula. SRK II and SRK/T had lowest MAE $(\mathbf{0 . 5 8} \pm \mathbf{0 . 4 4})$ for all eyes. SRK II had the lowest MAE for average $\mathbf{( 0 . 5 4 \pm 0 . 4 0 )}$ and short $(\mathbf{0 . 6 7} \pm \mathbf{0 . 5 4})$ eyes.SRK/T had the lowest MAE $(\mathbf{0 . 6 3} \pm \mathbf{0 . 4 8})$ for long eyes. BINKHORST II formula had highest MAE

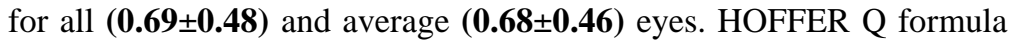
had highest MAE (0.76 $\pm \mathbf{0 . 6 5})$ for short eyes and SRK II had highest MAE (0.89 $\mathbf{0 . 6 4 )}$ for long eyes

Conclusion:SRK II and SRK/T are accurate formulas for average eyes.SRK II and HOLLADAY I are best formula of choice in short eyes.SRK/Tis accurate IOL formula for long eyes followed by HOLLADAY I and HOFFER Q .

Copy Right, IJAR, 2019,. All rights reserved.

\section{Introduction:-}

1. With the introduction of new surgical techniques, cataract surgery not only focuses on visual rehabilitation but it is now considered as a form of refractive surgery

2. Therefore accurate pre-operative intra ocular lens (IOL) power calculation is essential to achieve desired refractive outcomes

Corresponding Author:-V a n p kumari oruganti.

Address:-Junior Resident, Ophthalmology, Andhra Medical College, Visakhapatnam. 


\section{Aim:}

To evaluate and compare the accuracy of different intra ocular lens (IOL) power calculation formulas for predicting post-operative refraction in eyes of different axial lengths using Applanation A scan biometry

\section{Materials and methods:-}

1. Aprospective study conducted from May 2017 to July 2017 in department of ophthalmology , GREH ,AMC , Visakhapatnam in 100 eyes

2. Axial length (al) of eye is measured by ApplanationAscan and corneal power by Keratometer.

3. All eyes were divided into three groups according to AL: short $(<22.0 \mathrm{~mm})$, average $(22.0-25.0 \mathrm{~mm})$, and long $(>25.0 \mathrm{~mm})$ eyes

4. IOL power calculation was done using the five formulas SRKII, SRK/T, HOLLADAY1, HOFFERQ, and BINKHORST 2.

5. All patients were subjected to SICS with PCIOL implantation under local anaesthesia

6. The implanted power of IOL was based on SRK II formula

7. Final refraction was measured 6 weeks postoperatively

8. The post-operative spherical equivalent (se) was calculated and compared with predicted refractive error using each biometric formula.

\section{Inclusion criteria:}

All patients above 18 years of age admitted for cataract surgery

\section{Exclusion criteria:}

1. Combined procedures

2. $>2 \mathrm{D}$ of postoperative astigmatism

3. PC rupture

4. Past ocular surgeries

Figure 1:-Gender distribution:

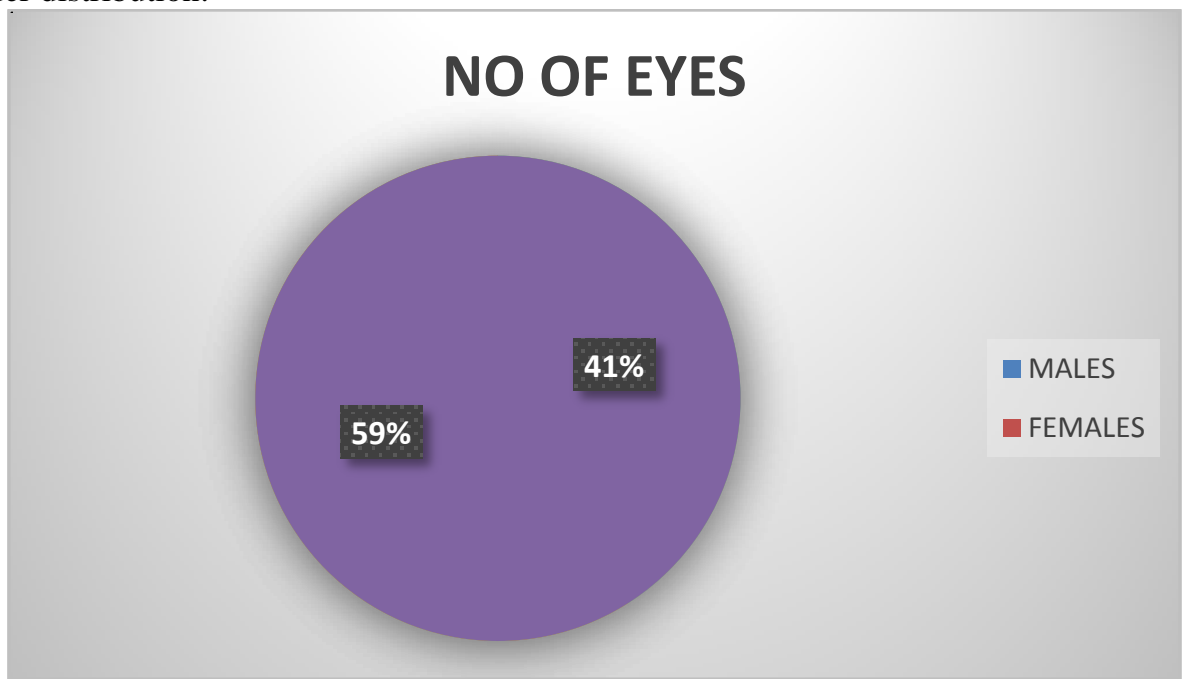

Age distribution:

Mean age was $62 \pm 3.2 y r s$ in the study.

Table1:-Based on AL, eyes were divided into 3 groups:

\begin{tabular}{|l|l|l|l|}
\hline & AL & No of eyes & Percentage \\
\hline Average eyes & $22-25 \mathrm{~mm}$ & 87 & $87 \%$ \\
\hline Short eyes & $<22 \mathrm{~mm}$ & 9 & $9 \%$ \\
\hline Long eyes & $>25 \mathrm{~mm}$ & 4 & $4 \%$ \\
\hline
\end{tabular}


Table 2:-Percentage of Refractive Errors (D) In Preoperative Power Prediction of Each Formula: 0-0.5 D

\begin{tabular}{|l|l|l|l|l|}
\hline & All eyes(100) & Average eyes(87) & Short eyes(9) & Long eyes(4) \\
\hline SRK II & $\mathbf{6 0}(\mathbf{6 0 \%})$ & $\mathbf{5 4}(\mathbf{6 2 \%})$ & $\mathbf{5 ( 5 5 . 5 \% )}$ & $1(25 \%)$ \\
\hline SRK/T & $56(56 \%)$ & $50(58 \%)$ & $4(44.4 \%)$ & $\mathbf{2 ( 5 0 \% )}$ \\
\hline HOLLADAY I & $54(54 \%)$ & $48(56 \%)$ & $4(44.4 \%)$ & $\mathbf{2 ( 5 0 \% )}$ \\
\hline HOFFER Q & $51(51 \%)$ & $45(52 \%)$ & $4(44.4 \%)$ & $\mathbf{2 ( 5 0 \% )}$ \\
\hline BINKHORST II & $48(48 \%)$ & $42(48 \%)$ & $\mathbf{5 ( 5 5 . 5 \% )}$ & $1(25 \%)$ \\
\hline
\end{tabular}

Table 3:-Percentage of Refractive Errors (D) In Preoperative Power Prediction of Each Formula: 0.5-1.0 D

\begin{tabular}{|l|l|l|l|l|}
\hline & ALL EYES(100) & AVERAGE EYES(87) & SHORT EYES(9) & LONG EYES(4) \\
& & & & \\
\hline SRK II & $86(86 \%)$ & $77(88.5 \%)$ & $7(77.7 \%)$ & $2(50 \%)$ \\
\hline SRK T & $86(86 \%)$ & $77(88.5 \%)$ & $6(66.6 \%)$ & $3(75 \%)$ \\
\hline HOLLADAY I & $87(87 \%)$ & $76(66.1 \%)$ & $7(77.7 \%)$ & $4(100 \%)$ \\
\hline HOFFER Q & $88(88 \%)$ & & $7(77.7 \%)$ & $4(100 \%)$ \\
\hline BINKHORST II & $82(82 \%)$ & $77(88.5 \%)$ & $5(55.5 \%)$ & $4(100 \%)$ \\
\hline
\end{tabular}

Table 4:-Mean absolute error (MAE) indiopters of each formula:

\begin{tabular}{|c|c|c|c|c|}
\hline & $\begin{array}{l}\text { ALL } \\
\text { EYES(100) }\end{array}$ & $\begin{array}{l}\text { AVERAGE } \\
\text { EYES(87) }\end{array}$ & SHORT EYES(9) & LONG EYES(4) \\
\hline SRK II & $0.58 \pm 0.44$ & $0.54 \pm 0.40$ & $0.67 \pm 0.54$ & $0.89 \pm 0.64$ \\
\hline SRK T & $0.58 \pm 0.44$ & $0.56 \pm 0.43$ & $0.70 \pm 0.63$ & $0.63 \pm 0.48$ \\
\hline
\end{tabular}




\begin{tabular}{|c|c|c|c|c|}
\hline HOLLADAY I & $0.66 \pm 0.48$ & $0.66 \pm 0.48$ & $0.68 \pm 0.48$ & $0.66 \pm 0.48$ \\
\hline HOFFER Q & $0.67 \pm 0.46$ & $0.55 \pm 0.44$ & $0.76 \pm 0.65$ & $0.66 \pm 0.52$ \\
\hline BINKHORST II & $0.69 \pm 0.48$ & $0.68 \pm 0.46$ & $0.75 \pm 0.72$ & $0.78 \pm 0.51$ \\
\hline
\end{tabular}

\section{Results:}

1. All formulas had a significantly lower MAE in comparison with BINKHORST II formula

2. SRK II and SRK/T had the lowest MAE (0.58 $\pm \mathbf{0 . 4 4 )}$ for all eyes.

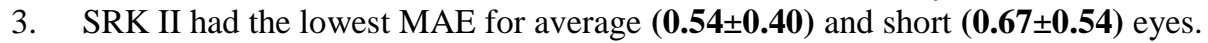

4. SRK/T had the lowest MAE $(\mathbf{0 . 6 3} \pm \mathbf{0 . 4 8})$ for long eyes. The BINKHORST II formula had the highest MAE for all $(0.69 \pm 0.48 \mathrm{~d})$ and average $(\mathbf{0 . 6 8} \pm \mathbf{0 . 4 6 d})$ eyes.

5. The HOFFER Q formula had the highest MAE (0.76 $\pm \mathbf{0 . 6 5 d})$ for short eyes and SRK II had the highest MAE $(\mathbf{0 . 8 9} \pm \mathbf{0 . 6 4 d})$ for long eyes.

\section{Discussion:}

1. Hoffer et al study published a series of 450 cases, concluded SRK/T, HOLLADAY I and HOFFER Q were statistically similar and all were better than SRK II with al >26 mm i.e in long eyes which is similar to our study.

2. Ozcura et al study conducted in turkey found that SRK II and SRK/T has least MAE in average and short eyes, SRK/T has least MAE in long eyes which is similar to our study.

3. Mithra et al study conducted in a subset of Indian myopes giving HOLLADAY I formula is accurate in myopesi.e in long eyes, where as in our studySRK/T is accurate in long eyes followed by HOLLADAY I and HOFFER Q .

\section{Conclusion:-}

1. SRK IIand SRK/T are accurate formulas for average eyes.

2. SRK IIand HOLLADAY I are best formula of choice in short eyes.

3. SRK/Tis the accurate IOL formula for long eyes followed by HOLLADAY I and HOFFER Q

4. Though IOL master is advanced technology in calculating IOL power,but it has disadvantage in medial opacities.thereforeApplanation A scan biometry is still considerated in medial opacity and in rural areas where advanced instruments not available.

\section{References:}

1. O "zcura, s. Aktas ,h. M. Sag ־dik, m. Tetikog -lu (2015) comparison of the biometric formulas used for applanation a-scan ultrasound biometry, intophthalmol,feb 2016:doi 10.1007/s10792-016-0195-6.

2. Hoffer kJ (1993) the hoffer q formula: a comparison of theoretic and regression formulas. J cataract refract surg 19:700-712.

3. Ashish mitra, eleshjain, aloksen, shubhitripathi ,a study regarding efficacy of various intraocular lens power calculation formulas in a subset of indian myopic population,indian journal of ophthalmol,2014;62;7;826-828. 